\title{
Gestão do conhecimento: ainda um obscuro objeto de desejo?
}

\author{
DOI: 10.3395/reciis.v4i5.336pt
}

\section{Paula Xavier Santos}

Casa de Oswaldo Cruz-Fiocruz, Rio de Janeiro, Brasil

paulaxs@fiocruz.br

\section{Maria Elisa Andries dos}

\section{Reis}

Escola Nacional de Saúde Sergio

Arouca-Fiocruz, Rio de Janeiro, Brasil elisar@fiocruz.br

\begin{abstract}
Resumo
A falta de fundamentos teórico-metodológicos centrais que configurem um referencial sobre a Gestão do Conhecimento pode ser a causa do caos informacional que se observa neste campo. Neste artigo, defendemos a relevância do uso do termo Gestão do Conhecimento como forma de distingui-la da abordagem da Gestão da Informação. O compartilhamento do conhecimento é um de seus pressupostos básicos, mas a compreensão da Gestão do Conhecimento como processo para apoio à tomada de decisão não pode ser desconsiderada. A Gestão do Conhecimento também nunca foi uma prática exclusiva das organizações privadas. No Brasil, iniciativas do Governo Federal demonstram que o assunto faz parte de sua pauta e, independentemente dos diferentes estágios de implementação em que se encontra nas instituições, existe a preocupação de construção de uma política com diretrizes e estratégias claramente definidas. Esta visão deixa claro que o importante para o desenvolvimento das sociedades, das organizações e dos indivíduos nos dias atuais é o conhecimento e sua aplicação. No caso das instituições públicas, o conhecimento aplicado é propulsor de processos de produtividade e inovação.
\end{abstract}

Palavras-chave

gestão do conhecimento; gestão da informação; administração pública
A Gestão do Conhecimento (GC) como objeto de pesquisa ou prática a ser adotada nos ambientes corporativos torna necessária a revisão e análise da produção científica deste campo, que apesar de tão difundido e em ampla ascensão, ainda se apresenta como obscuro e indefinido em seus preceitos fundamentais.

A percepção que gira em torno da área, ainda que como uma afirmação empírica, é a de que apesar do interesse cada vez maior de organizações em projetos e iniciativas em GC, assim como o número crescente de publicações, eventos e cursos especializados, ainda prevalece a falta de consistência sobre os fundamentos teórico-metodológicos centrais que configurem um referencial sobre o campo.

Uma base teórica referencial consistente é fundamental para a legitimação e consolidação da área como conhecimento científico. Controvérsias sempre existirão, pois são inerentes ao processo de produção do conhecimento. Entretanto, diferentes correntes de pensamento, reflexões e aplicações deverão articular-se de forma a resultar num conhecimento integrado e evolutivo sobre a questão.

Como contribuição a esta revisão sobre o tema da GC, este ensaio parte das bases conjunturais que contribuíram 
para a relevância e a necessidade da GC nos dias atuais. Em seguida buscamos o entendimento da GC como um processo evolutivo relacionado à Gestão da Informação. No terceiro tópico, sem a intenção de realizar uma revisão de literatura exaustiva, procuramos fazer uma análise crítica dos principais aspectos que permeiam os conceitos de GC. Alguns exemplos de iniciativas em desenvolvimento de GC na administração pública e seu sentido são explorados na quarta parte do trabalho, como forma de ampliar as possibilidades de aplicação da GC para além das organizações privadas. Por fim, concluímos apontando as perspectivas que podem, se efetivadas, trazer contribuições para a consolidação da GC.

\section{Sociedade em rede: novo paradigma}

Vivemos um momento único na história da humanidade. Um momento de transformações desenhadas pelas Tecnologias da Informação e da Comunicação (TIC), em que a nova configuração econômica, política, social e cultural ainda não foi inteiramente desvendada e a velha ordem já foi profundamente alterada. O impacto das transformações é sentido em várias dimensões das atividades humanas, inclusive nos processos de trabalho, devido ao acesso cada vez mais amplo às informações e à possibilidade de comunicação independente do tempo e da distância.

A partir do início dos anos 1990, a disseminação da Internet como sistema de comunicação e de acesso à informação, somada ao emprego maciço das demais TICS baseadas em computador, vem afetando todos os domínios sociais. A Internet, em particular, tornou-se a alavanca na transição para uma nova forma de sociedade, a sociedade em rede.

O divisor de águas é por volta dos anos 1970. Foi nesta década que três processos inauguraram uma nova estrutura social baseada em rede: as exigências da economia por flexibilidade administrativa e por globalização do capital, da produção e do comércio; as demandas da sociedade, em que os valores da liberdade individual e da comunicação aberta tornaram-se supremos; e os avanços extraordinários na computação e nas telecomunicações possibilitados pela revolução microeletrônica (CASTELLS, 2003).

Segundo Castells, o conceito de paradigma tecnológico - elaborado por Carlota Perez, Christopher Freeman e Giovanni Dosi, com a adaptação da análise clássica das revoluções científicas feita por Thomas Kuhn - ajuda a organizar a essência da transformação tecnológica atual à medida que interage com a economia e a sociedade. Um paradigma econômico e tecnológico é um agrupamento de inovações técnicas, organizacionais e administrativas inter-relacionadas, cujas vantagens devem ser descobertas não apenas em uma nova gama de produtos e sistemas, mas também, e sobretudo, na dinâmica da estrutura dos custos relativos de todos os possíveis insumos para a produção (FREEMAN apud CASTELLS, 1999).

Freeman vê a mudança contemporânea de paradigma como a transferência de uma tecnologia baseada principalmente em insumos baratos de energia para uma outra, que se baseia predominantemente em insumos baratos de informação derivados do avanço da tecnologia em microeletrônica e telecomunicações (FREEMAN apud CASTELLS, 1999).

No rastro da revolução tecnológica, surgiu nas últimas décadas uma nova economia em escala global. Castells (1999) classifica esta nova economia de informacional e global porque sob novas condições históricas, a produtividade é gerada e a concorrência é feita em uma rede global de interação. Segundo o autor, é informacional porque a produtividade e a competitividade dependem da capacidade de gerar, processar e aplicar de forma eficiente a informação com base em conhecimentos. E é global porque as principais atividades produtivas, o consumo e a circulação, assim como seus componentes (capital, trabalho, matéria-prima, administração, informação, tecnologias e mercados) estão organizados em escala global, diretamente ou mediante uma rede de conexões entre agentes econômicos (CASTELLS, 1999).

A revolução tecnológica, entretanto, é também uma revolução informacional. Segundo Lojkine (1999), trata-se de uma mutação revolucionária para toda a humanidade, mutação só comparável à invenção da ferramenta e da escrita [...] e que ultrapassa largamente a da revolução industrial (LOJKINE, 1999). Ele defende ainda que é o surgimento de uma civilização não mais dividida entre aqueles que produzem e os que comandam, mas entre aqueles que detêm o conhecimento e os que são excluídos deste exercício (LOJKINE, 1999).

A revolução em curso toma de assalto as relações entre os humanos e suas ferramentas. As fronteiras temporais, espaciais, associativas e formadoras de identidade se dissolvem na Internet. A meta de saber da nossa civilização se transformou em um dilúvio de informação. Se, por um lado, a Internet torna a informação instantaneamente disponível em todo planeta, por outro, o problema atual consiste justamente 
na enorme pobreza de informações substanciosas em conteúdo, em relação à enorme quantidade de informações insignificantes difundidas pelo mass media (LOJKINE, 1999).

O momento atual é caracterizado como uma revolução devido às novas possibilidades que a união de tecnologia e conteúdo podem ocasionar. Santos (2002) defende que assim como as redes tecnológicas alteram por completo a noção de espaço e tempo, a tecnologia exerce uma ação direta sobre a entidade informação, transformando-a, ou mais precisamente, criando novas possibilidades de aplicação e uso deste objeto jamais visto (SANTOS, 2002).

O fenômeno denominado "explosão da informação", que representa este aumento no volume e no ritmo que o conhecimento é produzido, cria uma nova situação: a quantidade de informação produzida sobre uma determinada área do saber se torna difícil de administrar, forçando a criação de ferramentas e instrumentos que facilitem o acesso a estes estoques informacionais.

No ambiente das organizações, o gerenciamento destes estoques informacionais tem por objetivo utilizá-los como recursos estratégicos, conferindo à informação o seu verdadeiro valor: auxiliar o homem a pensar, organizar, decidir e agir.

\section{Da gestão da informação à gestão do conheci- mento: um breve histórico}

A percepção de que a informação é o ativo mais importante de uma organização, tanto no que diz respeito aos estoques registrados quanto ao conhecimento individual, cristalizou-se no fim do século XX. A trajetória do novo paradigma teve início nos anos 1960 e seu ápice aconteceu nos anos 1980, quando os governos dos Estados Unidos e da Inglaterra formalizaram, através de atos legais, a gerência da informação como recurso organizacional.

Até a primeira metade dos anos 1980, equipamentos e profissionais de informática eram caros, e o objetivo principal da informatização era modelar e padronizar informações tratadas pelos sistemas. O baixo retorno dos altos investimentos determinou a mudança de rumo. O governo americano decidiu adotar nova estratégia, agregando políticas e procedimentos para gerenciar todo o ciclo da informação: desde a geração, a coleta, a organização e o processamento, até a sua disseminação e o seu uso.

A partir da publicação do Ato Legal "Circular A-130", em 1985, pelo Federal Register, o tratamento da informação ganhou novo status, deixando de estar relacionado unicamente aos aspectos tecnológicos. Resultado: o leque de questões se ampliou para discussões sobre terminologia, classificação, grau de sigilo, tabelas de temporalidade, privacidade e direitos autorais.

A idéia da informação como ferramenta estratégica evoluiu quase que naturalmente depois que o gerenciamento da informação mostrou resultados em relação à eficiência operacional, evitando desperdícios e automatizando processos. A nova visão extrapolou os muros das instituições governamentais e se espalhou por grandes corporações privadas, que passaram a instituir uma estrutura formal, em geral ligada à Presidência ou ao alto escalão hierárquico, para cuidar da gestão dos recursos de informação.

Nesta nova perspectiva, o termo utilizado passa de Gestão da Informação para Gerência dos Recursos Informacionais (GRI), cuja principal finalidade era o acompanhamento eficiente de processos, o apoio à tomada de decisões estratégicas e a obtenção de vantagem competitiva em relação aos concorrentes. Para tanto, além do gerenciamento de todo ciclo da informação, o monitoramento das mudanças foi incluído na pauta de prioridades.

Em seu artigo "Esquemas Conceituais e Estratégicos para a Gerência da Informação", Cronin (1990) define a Gerência dos Recursos Informacionais como a maneira eficaz de tratar integrativamente a informação interna e externa para uso estratégico pelos tomadores de decisão nas organizações, visando a otimizar a performance dessas instituições e sintonizá-las com o ambiente externo (CRONIN, 1990).

Vieira (apud SANTOS, 2002) complementa a visão de Cronin descrevendo o gerente de recursos informacionais como [...] um estrategista que deve ter, portanto, a capacidade de captação, compreensão, análise crítica e interpretação da realidade, dentro de uma perspectiva histórica, tal como essa realidade se apresenta, sob a forma de eventos, notícias, idéias, dados ou documentos. Esse gerente deve trabalhar dialeticamente os conteúdos de análise e síntese, medindo a relação entre sua organização e o ambiente (VIEIRA, 1990).

Enquanto objeto de investigação, a GRI se configura como área de interesse de diferentes campos do conhecimento. Uma de suas áreas de origem é a Administração de Empresas. Na nova configuração econômica, a Administração passa a lidar com o crescimento das unidades de produção, induzindo à sistematização e à criação de fluxos de informação, dos quais administradores e gerentes dependem para uma administração eficiente. Novas teorias e métodos de gestão organizacional, somados ao desenvolvimento das tecnologias 
da informação, desenharam esta nova competência baseada na informação no ambiente das empresas.

A Ciência da Computação contribuiu para a GRI desenvolvendo aplicações como Sistemas Gerenciais, Inteligência Artificial e Sistemas Especialistas - ferramentas tecnológicas e de metodologias organizacionais fundamentais para o apoio à tomada de decisão e o planejamento estratégico nas empresas. A Economia, por sua vez, destacou como objeto de estudo o novo modo de desenvolvimento capitalista, caracterizado pelo informacionalismo, que considera a informação como principal fonte de produtividade.

E, por fim, a abordagem da Ciência da Informação em relação à informação e ao conhecimento tem ênfase no processo de gestão, indicado através da temática knowledge management. O objetivo é lidar com os problemas relacionados à organização, ao acesso e à disseminação da informação. Historicamente, a Ciência da Informação é constituída e reconhecida oficialmente enquanto ciência em 1962, período de grande avanço científico e tecnológico após a II Guerra Mundial. Este período foi marcado pela "explosão da informação" - crescimento exponencial da produção de conhecimento registrado (PINHEIRO, 1997).

Marchand e Horton (apud SANTOS, 2002) apresentam um quadro que ilustra a evolução da GRI no ambiente organizacional:

\section{Estágios de desenvolvimento da gerência da infor- mação estratégica}

\author{
Estágio 5 \\ Gerência da Informação \\ Estratégica
}

Estágio 4

Análise e inteligência estratégica do negócio concorrente

\section{Estágio 3}

Gerenciamento de Recursos de Informação da organização

Estágio 2

Gerenciamento da tecnologia automatizada

Estágio 1

Gerenciamento de paperwork

Fonte: (SANTOS, 2002)
Da mesma forma que a tecnologia da informação passou por diferentes estágios definidos de acordo com seu uso, este quadro demonstra a evolução do processamento da informação no ambiente empresarial. Num primeiro momento, o objetivo era organizar documentos para prover acesso e minimizar custos; com a automação, a expectativa era conferir agilidade a este processo. O estágio da gerência dos recursos informacionais se preocupa com a administração da informação, e não do papel. Este enfoque enfatiza nitidamente o conteúdo dos registros, chegando-se até a agregação de inteligência aos recursos de informação através de análise e interpretação dos dados.

A trajetória da Gestão da Informação e do Conhecimento como campo de investigação e aplicação apresenta três abordagens distintas: num primeiro momento, a ênfase era no processamento de dados; em seguida, a informação assume caráter de recurso estratégico; e, por fim, nos dias atuais, a perspectiva passou a ser o gerenciamento não só da informação, mas, principalmente, a conversão do conhecimento tácito em explícito.

Até perceberem a necessidade de agregar o conhecimento ao processo, as empresas percorreram longo caminho. Foi o último degrau de uma cadeia de investimentos, que começou com a valorização do dado e, em seguida, da informação. A diferença entre dado, informação e conhecimento remete a uma questão de grau. Para Davenport e Pruzak (1998),

[...] ficou claro que aquilo que nossos clientes desejavam acima de qualquer coisa era insight. Eles estavam buscando práticas melhores, idéias novas, sinergias criativas e processo de descoberta; algo que informação, por mais bem administrada que seja, não pode fornecer (DAVENPORT et al., 1998).

Nesta perspectiva surge o conceito de GC, agregando o conhecimento tácito como recurso a ser gerenciado.

\section{Análise crítica dos principais conceitos}

Nesta seção destacamos alguns dos aspectos relacionados e que perpassam a maior parte dos conceitos e definições sobre GC, a fim de traçar uma síntese de elementos considerados consensuais.

Uma visão atual de Gestão do Conhecimento, abrangendo a maioria destes aspectos, é apresentada por Regina 
Cianconi (2003), em sua tese de doutorado:

Gestão do Conhecimento pode ser entendida como ações sistemáticas para facilitar o compartiIhamento do conhecimento, estando associada ao processo de criação, organização, difusão e uso do conhecimento, envolvendo políticas, metodologias e tecnologias para seu compartilhamento, mapeamento e avaliação. (CIANCONI, 2003).

Um dos aspectos motivadores para a GC foi a constatação de que o valor das ações das empresas incorpora "intangíveis" tais como: o valor das patentes, a capacidade de inovação, o talento dos funcionários, as suas relações com os clientes, entre outros fatores.

A introdução da idéia de conhecimento tácito como recurso a ser gerenciado é a grande inovação apresentada na abordagem de Gestão do Conhecimento. Mais ainda, a noção de que não basta gerenciar estes recursos, mas estudar seus processos de criação, é introduzida por Ikujiro Nonaka e Hirotaka Takeuchi em seu livro "Criação de Conhecimento na Empresa: como as empresas japonesas geram a dinâmica da Inovação".

Segundo os autores, apesar de a discussão sobre GC ser tema recorrente na literatura ocidental, nenhum dos autores se preocupou em discutir o processo de criação do conhecimento, mas apenas o processamento de informações e conhecimento. Isso decorre do fato de que no Ocidente as organizações são vistas como máquinas de processamento de informações, enquanto no Japão as empresas são entendidas como organismos vivos. Na visão do Ocidente, segundo os autores, o conhecimento é entendido como necessariamente explícito - algo formal e sistemático.

O conhecimento explícito pode ser expresso em palavras e números, e facilmente comunicado e compartilhado sob a forma de dados brutos, fórmulas científicas, procedimentos codificados ou princípios universais (NONAKA et al., 1997).

Dicotomicamente, nas empresas japonesas o conhecimento é entendido como sendo basicamente tácito - algo dificilmente visível e exprimível. O conhecimento tácito é altamente pessoal e difícil de formalizar, o que dificulta sua transmissão e seu compartilhamento.

Conclusões, insights e palpites subjetivos incluem-se nesta categoria de conhecimento. Além disso, o conhecimento tácito está profundamente enraizado nas ações e experiências de um indivíduo, bem como em suas emoções, valores ou ideais (NONAKA et al., 1997).

O segundo aspecto a se ressaltar é o de que esta distinção entre conhecimento explícito e tácito demarca a diferença entre as abordagens de GI e GC. A GC, além de ter o conhecimento como objeto a ser gerenciado e compartilhado, pressupõe processos e estratégias para criação de novos conhecimentos. Uma corrente de autores critica o uso do termo GC, argumentando que conhecimento é inerente ao ser humano, não sendo passível de se transferir diretamente. Sua gestão por parte das organizações ocorre no sentido da facilitação, direcionamento, estímulo ao aprendizado, compartilhamento e avaliação.

Sem dúvida, a aquisição de conhecimento envolve processos cognitivos individuais que não passíveis de serem gerenciados. No entanto, o grande diferencial que a GC propõe fica fortemente demarcado justamente pelo uso do termo conhecimento. Neste sentido, podemos considerar a CC como um novo campo, uma vez que traz uma abordagem original. Mesmo assim, é importante pensar a GC de forma intrinsecamente relacionada à Gestão da Informação, representando, um dos elos da cadeia evolutiva desta área.

A relação entre GC e Gl é muitas vezes esquecida, mas não pode ser desconsiderada, uma vez que revela algumas considerações que merecem destaque. A primeira delas é que não existe GC sem Gl. A GC deve contemplar o gerenciamento tanto dos recursos informacionais (conhecimento explícito) como do conhecimento tácito, que por sua vez deverá passar pelo processo de conversão para conhecimento explícito. Caso contrário, não apresentará resultados. Se o conhecimento tácito deverá se tornar explícito, fica mais do que óbvio a necessidade de GI.

Conhecendo um pouco a evolução das áreas da Biblioteconomia e da Documentação, é possível traçar um paralelo entre suas abordagens em relação aos objetos informação e conhecimento e a evolução das áreas da GI e GC. Num primeiro momento, as bibliotecas estavam preocupadas com a ordenação dos documentos enquanto suporte físico. A recuperação da informação mediada por instrumentos metodológicos e tecnológicos foi desenvolvida para dar conta desta questão. Por isso, era garantida a localização do documento enquanto suporte físico através de tabelas de classificação, e nem sempre a recuperação por assunto contava com instrumentos eficientes.

Posteriormente, os instrumentos de recuperação passaram a ser desenvolvidos a partir do entendimento de que o documento está inserido num universo de conhecimento 
e este universo precisa ser representado. Desta forma, a representação da informação não indica somente a localização física do documento mas, sobretudo, o universo de conhecimento tratado. O enfoque passa a ser a informação contida nos documentos e não mais o documento em si.

Atualmente, as unidades gerenciadoras de informação sabem que para satisfazer as necessidades de seus usuários é preciso mais do que informação codificada e registrada. Os usuários estão em busca de informação contextualizada que contribua para a produção de significados e, consequentemente, de conhecimento.

Da mesma forma, as organizações construíram abordagens em relação à informação; primeiro, com foco no gerenciamento de documentos, depois, da informação desprendida de seu suporte físico e, atualmente, está em busca do que se entende por GC, ultrapassando os estoques informacionais, registrados e codificados, e agregando o conhecimento tácito como recurso organizacional.

O conceito de GC provoca uma mudança de foco na tentativa de desenvolver sistemas inteligentes para desenvolver pessoas inteligentes. Isso é o que torna a GC tão atraente para as organizações. Enquanto o foco dos sistemas de informação é voltado para o gerenciamento do conhecimento explícito, a GC traz uma nova dimensão, que revela a necessidade de gerenciar o conhecimento tácito através do foco nas pessoas e na sua capacidade de transferir conhecimento. Essa distinção pode facilmente ser verificada nas práticas alavancadas por cada uma das abordagens. Isso porque, se o foco muda da informação para o conhecimento, as ferramentas e os processos de mapeamento e gerenciamento naturalmente também se modificam.

O quarto ponto a ser levantado em relação aos conceitos de GC é sua associação com os ambientes corporativos. Nestes ambientes, a GC é vista como modelo de gestão baseado no estímulo ao compartilhamento intensivo de experiências, competências e conhecimento, bem como ao gerenciamento dos estoques informacionais visando à criação de conhecimento que subsidiem as ações organizacionais.

A primeira ressalva que fazemos a este tipo de entendimento é a de que é preciso alargar este olhar. A GC, tanto como campo de investigação quanto como aplicação, possui princípios teórico-metodológicos que podem ser aplicados em diferentes ambientes. Santos, em sua tese de doutorado "Gestão do Conhecimento das Práticas Científicas: a construção de redes de informações estratégicas para a legitimação dos campos científicos" (2002), investiga a GC como instrumento de apoio aos processos decisórios estabelecidos com a finalidade de legitimação dos campos científicos.
A compreensão da Gestão do Conhecimento segundo o processo pelo qual as informações estratégicas são identificadas, analisadas e interpretadas com a finalidade de gerar novas informações e conhecimentos que apóiem os processos de tomada de decisão e ação, demonstra que este processo pode ser aplicado em outros ambientes que não o empresarial. Os fluxos informacionais são estabelecidos por todas as atividades humanas e a Gestão do Conhecimento pode ser aplicada de acordo com a finalidade de cada empreendimento, seja científico, empresarial ou político (SANTOS, 2002).

A quinta consideração desta análise é a de que as práticas de GC, apesar de baseadas no compartilhamento do conhecimento, possuem um leque de finalidades, entre elas a geração de informação estratégica como subsídio para a tomada de decisão. Neste caso, informação estratégica pode significar informação de caráter sigiloso. Portanto, não são todos os casos em que a GC visa o compartilhamento de informações como finalidade máxima. Este pode ser uma das etapas do processo de geração de informações estratégicas de caráter restrito.

O último aspecto que queremos destacar é que, de maneira geral, os conceitos sobre GC associam esta prática ao uso das tecnologias de informação e de comunicação. A definição do papel da tecnologia no processo de GC nem sempre é claro. Observamos que muitas definições de GC enfatizam a tecnologia como resposta aos problemas levantados pela GC. Na economia informacional, no entanto, a necessidade maior reside no gerenciamento da informação e do conhecimento e não na mera automação de processos informacionais.

Segundo este ponto de vista, uma empresa inteligente não é aquela capaz apenas de fazer uso da mais moderna e completa tecnologia; mas, principalmente, aquela que sabe usar as capacidades de análise, interpretação e síntese da informação e do conhecimento, que são aspectos meramente intelectuais. Não podemos esquecer que as tecnologias não fabricam idéias. Até que provem o contrário, são os homens que a concebem (autor desconhecido).

Em consonância com os fundamentos da GC, fica claro que suas práticas abordam o conhecimento como um produto social, podendo ser socialmente criado e transformado pela ação das pessoas, por meio da colaboração, do 
compartilhamento, de modo coletivo. Assim, a GC pode, se adequadamente implementada, contribuir para a democratização, para maior participação e aumento do conhecimento individual, coletivo e organizacional. Nesta perspectiva, a discussão sobre a GC na esfera pública assume grande valor.

\section{Governo que aprende: GC na esfera pública}

A pergunta é: qual o espaço que cabe ao setor público na sociedade brasileira que se quer? Paulo Fresneda, pesquisador da Embrapa, declarou em discurso no $2^{\circ}$ Congresso de Gestão do Conhecimento na Esfera Pública (Congep) que o setor público tem uma característica muito importante neste debate sobre Gestão do Conhecimento. As principais infraestruturas de que dispomos nos dias atuais - seja nos transportes, nas telecomunicações ou no setor energético - foram criadas em projetos da década de 1970 por organizações públicas como Serpro, Petrobras, Furnas etc.

Ninguém discorda de que as organizações públicas brasileiras estão em falta com muita coisa. Falta memória organizacional, faltam processos de qualidade e eficiência, falta cultura de atendimento ao cliente, falta até mesmo autoconfiança e esperança no futuro. Mas, por outro lado, há uma enorme riqueza em conhecimento tácito de especialistas bem formados e com décadas de experiência.

A finalidade da GC é melhorar o desempenho das empresas, sejam elas privadas ou públicas. Seguindo a perspectiva apresentada ao longo deste artigo de que a GC representa mudanças centradas no comportamento das pessoas e na cultura organizacional, é preciso considerar em seu processo de implementação as especificidades constituintes dos diferentes ambientes organizacionais.

Partindo deste princípio, pode-se dizer que não existe um modelo único de GC. Cada organização deve desenvolver seu próprio modelo, levando em consideração as especificidades de sua cultura organizacional e as motivações para um projeto de GC.

Nos trabalhos apresentados no Congep, as empresas deixaram claro que o perfil organizacional foi o primeiro fator a ser considerado em seus programas de GC. A grande variedade de competências para o cumprimento da missão institucional conduziu o Banco Central, a Caixa Econômica Federal (CEF) e o Banco do Brasil a implementar a gestão por competências. Já a faixa etária alta dos empregados e a aproximação de aposentadoria para muitos técnicos de alto nível motivaram a Petrobras a estimular a prática de mentoring e de Comunidades de Práticas Virtuais.

Também no Congep, a Coordenadora da Universidade Corporativa da CEF, Sônia Goulart, informou que nos próximos três anos sete mil pessoas de setores estratégicos irão se aposentar. Como fazer para reter na empresa o conhecimento destes profissionais é a grande preocupação da organização no momento. Ainda neste evento outras iniciativas em andamento no âmbito do governo foram apresentadas, descritas a seguir:

- Ação do Comitê Técnico de Gestão do Conhecimento do Governo Eletrônico - Capacitação de 100\% dos gestores públicos dos 19 ministérios em Gestão do Conhecimento, denominado Programa de Desenvolvimento de Gestores Públicos em Gestão do Conhecimento (PDGC).

- Oficinas sobre Educação Corporativa promovidas pelo Ministério do Desenvolvimento, Indústria e Comércio Exterior;

- Ciclo de palestras sobre "Gestão Estratégica da Informação e do Conhecimento 2004" - constituída por 15 palestras e mais de 600 participantes. O objetivo é elaborar uma política de GC e da Informação para a Câmara dos Deputados.

- A CEF mapeou 38 mil pessoas e seus conhecimentos básicos e específicos visando atividades de transferência de conhecimento. A opção metodológica da Caixa foi o reconhecimento de talentos, através da construção do Banco de Talentos. A intenção foi a de reconhecer e valorizar estes talentos, contribuindo para acabar com a impressão externa de que "o governo não sabe nada".

- Partindo do princípio de que a instituição pública tem que ser útil para a sociedade e, portanto, centrada nos resultados, a Embrapa, baseada no conceito de Inovação como Idéia + implementação + resultado, vem desenvolvendo seu programa de Gestão do Conhecimento.

- A Eletronuclear, seguindo recomendação do Conselho Nacional de Política Externa, implantou um programa de GC que teve início com dois projetos: a) Gerenciamento Eletrônico de Documentos de Engenharia (EDMS); b) Projeto de Conhecimento Tácito - Árvores do Conhecimento.

Mesmo considerando que os programas e práticas de GC são desenvolvidos de modo particular, achamos que num certo nível de discussão é possível agregar características que distinguem os ambientes públicos e privados. 
Um estudo publicado pelo Instituto de Pesquisa Econômica e Aplicada (IPEA), denominado "Governo que aprende: Gestão do Conhecimento em organizações do executivo Federal" (BATISTA, 2004), relata que em análise do PPA 2000/2003 é mostrado que existe uma relação direta entre as deficiências gerenciais das organizações públicas e o êxito dos programas governamentais. Dito de outra forma, a melhoria da gestão das organizações públicas é fundamental para o êxito da gestão governamental. Dentre as deficiências apontadas pelo relatório, destacam-se:

- ausência de foco no cliente do serviço público (cidadão);

- processos e atividades não documentados e nem otimizados;

• servidores que não conhecem o papel da organização;

- informações não circulam de maneira ágil e correta entre servidores e setores;

- inexistência da preocupação constante com inovação e mudança.

O documento do IPEA tem por objetivo discutir o conceito de GC e sua importância para a Administração Pública, além de identificar o estágio de implementação da GC em seis organizações do executivo federal: Banco do Brasil, Banco Central do Brasil, Caixa Econômica Federal, Empresa Brasileira de Pesquisa Agropecuária (Embrapa), Serviço de Processamento de Dados (Serpro) e Petróleo Brasileiro (Petrobras).

Estas organizações foram escolhidas por serem consideradas de referência em algumas práticas de GC. O autor explica que não foram utilizadas organizações da Administração Direta em sua análise devido ao baixo nível de conscientização entre dirigentes sobre a importância da GC. $\mathrm{E}$, conseqüentemente, devido à falta de priorização e de alocação de recursos em projeto de tal natureza. Por seu turno, empresas públicas e sociedades de economia mista ocupam posição de vanguarda no desenvolvimento gerencial, e, por isso, estão cientes da GC. São estas, inclusive, as empresas mais premiadas pelo Prêmio Nacional de Gestão Pública desde sua criação, em 1998.

Segundo o autor do estudo, a GC nestas organizações deve ser vista de forma mais ampla que em empresas do setor produtivo. O papel da GC na Administração Pública transcende a finalidade de melhorar o desempenho organizacional, cumprindo importante papel na função da sociedade democrática e na inserção do país na economia mundial.

\section{GC nas empresas privadas $X$ públicas}

\begin{tabular}{|l|l|}
\hline Empresas privadas & Empresas públicas \\
\hline $\begin{array}{l}\text { Melhorar qualidade de } \\
\text { produtos e serviços }\end{array}$ & $\begin{array}{l}\text { Tratar de maneira adequada e com rapidez } \\
\text { desafios inesperados }\end{array}$ \\
\hline $\begin{array}{l}\text { Aumentar a satisfação } \\
\text { dos clientes }\end{array}$ & $\begin{array}{l}\text { Preparar cidadãos, organizações não- } \\
\text { governamentais e outros atores sociais } \\
\text { para atuar como parceiros do Estado na } \\
\text { elaboração e implementação de politicas } \\
\text { públicas }\end{array}$ \\
\hline $\begin{array}{l}\text { Inovar, elevar a } \\
\text { produtividade e } \\
\text { rentabilidade }\end{array}$ & $\begin{array}{l}\text { Promover a inserção social, a redução das } \\
\text { desigualdades sociais e um nível aceitável } \\
\text { de qualidade de vida para a população } \\
\text { por meio da construção, manutenção e } \\
\text { ampliação do capital social e do capital } \\
\text { intelectual das empresas }\end{array}$ \\
\hline $\begin{array}{l}\text { Melhorar o } \\
\text { desempenho em } \\
\text { relação à concorrência }\end{array}$ & $\begin{array}{l}\text { Tornar as organizações competitivas em } \\
\text { todas as áreas do conhecimento }\end{array}$ \\
\hline & $\begin{array}{l}\text { Criar uma sociedade competitiva na } \\
\text { economia regional e global por meio da } \\
\text { educação dos cidadãos para que eles se } \\
\text { tornem trabalhadores competentes do } \\
\text { conhecimento }\end{array}$ \\
\hline
\end{tabular}

Fonte: Este quadro foi elaborado com base no documento "Governo que aprende: Gestão do Conhecimento em organizações do executivo Federal" (BATISTA, 2004)

Ainda segundo Batista (2004), os fatores críticos para implementação da GC na esfera pública são:

- as práticas de GC devem estar alinhadas e devem fazer parte do modelo de gestão das organizações;

- as práticas de GC devem ser disseminadas em toda a organização:

- os funcionários devem ser capacitados e "aculturados" para utilizar ferramentas de GC;

- a estratégia de GC deve ser constantemente avaliada;

- deve existir estrutura formal de apoio para coordenar as iniciativas;

- deve haver continuidade administrativa;

- são necessários o comprometimento e o patrocínio da alta administração;

- deve-se procurar um sistema de reconhecimento para apoiar a estratégia de GC;

- deve-se ter clareza na comunicação dos objetivos a serem atingidos.

A GC nas organizações públicas é tema que tem merecido pouca atenção dos analistas. É preciso avançar não somente 
no mapeamento de iniciativas, mas na reflexão do sentido e benefícios da GC neste contexto.

\section{Conclusão}

Defendemos a relevância do uso do termo Gestão do Conhecimento como forma de distingui-la da abordagem da Gestão da Informação. Em nosso entendimento, a GC é muito mais uma nova abordagem do que um novo campo, não podendo estar dissociada da Gı. O compartilhamento de conhecimento nem sempre é a finalidade deste processo, podendo ser considerado uma de suas etapas. Foi dito ainda que os princípios teórico-metodológicos da GC podem ser aplicados em diversos empreendimentos e, não exclusivamente, nos ambientes corporativos.

As informações que trouxemos sobre as iniciativas do governo em GC demonstram que este assunto faz parte de sua pauta e, independentemente dos diferentes estágios de implementação em que a GC se encontra nas organizações, existe a preocupação de construção de uma política de gestão do conhecimento com diretrizes e estratégias claramente definidas.

Essa visão de GC deixa claro que o importante para o desenvolvimento das sociedades, das organizações e dos indivíduos nos dias atuais é o conhecimento e sua aplicação. No caso das organizações, o conhecimento aplicado é propulsor dos processos de produtividade e inovação. Sem dúvida, a Gestão do Conhecimento é um caminho que pode nos ajudar neste processo, tanto nas organizações privadas, como públicas.

\section{Referências}

BATISTA, F.F. Governo que aprende: gestão do conhecimento em organizações do executivo federal. Brasília: Instituto de Pesquisa Econômica Aplicada, 2004.

BAUMAN, Z. Globalização: as conseqüências humanas. Rio de Janeiro: Jorge Zahar, 1999.

CASTELLS, M. A sociedade em rede. São Paulo: Paz e Terra, 1999.
CASTELLS, M. A galáxia da Internet. Rio de Janeiro: Jorge Zahar, 2003.

CIANCONI, R. Gestão do conhecimento: visão de indivíduos e organizações no Brasil. 2003. Tese (Doutorado em Ciência da Informação) - Instituto Brasileiro de Informação Científica e Tecnológica, Escola de Comunicação, Universidade Federal do Rio de Janeiro, Rio de Janeiro, 2003.

CRONIN, B. Esquemas conceituais e estratégicos para a gerência da informação. Revista da Escola de Biblioteconomia da UFMG, v.19, n.2, p.195-220, 1990.

DAVENPORT, T.; PRUSAK, L. Conhecimento empresarial: como as organizações gerenciam seu capital. Rio de Janeiro: Campus, 1998.

LÉVY, P. As tecnologias da inteligência: o futuro do pensamento na era da informática. São Paulo: Editora 34, 1993.

LÉVY, P. Cibercultura. São Paulo: Editora 34, 1999.

LOJKINE, E.J. A revolução informacional. São Paulo: Cortez, 1999.

NONAKA, I.; TAKEUCHI, H. Criação de conhecimento na empresa: como as empresas japonesas geram a dinâmica da inovação. Rio de Janeiro: Campus, 1997.

PINHEIRO, L.V.R. A ciência da informação entre sombra e luz: domínio epistemológico e campo interdisciplinar. 1997. Tese (Doutorado em Ciência da Informação) - Instituto Brasileiro de Informação Científica e Tecnológica, Escola de Comunicação, Universidade Federal do Rio de Janeiro, Rio de Janeiro, 1997

SANTOS, P. X. Gestão do conhecimento das práticas científicas: a construção de redes de informações estratégicas para a legitimação dos campos científicos. 2002. Tese (Doutorado em Ciência da Informação) - Instituto Brasileiro de Informação Científica e Tecnológica, Escola de Comunicação, Universidade Federal do Rio de Janeiro, Rio de Janeiro, 2002. 